\title{
A phase Illb, randomised, parallel-group study: the efficacy, safety and tolerability of once-daily umeclidinium in patients with asthma receiving inhaled corticosteroids
}

Edward Kerwin', Steven Pascoe ${ }^{2}$, Zelie Bailes ${ }^{3}$, Robert Nathan ${ }^{4}$, David Bernstein ${ }^{5,6}$, Ronald Dahl7, Robyn von Maltzahn ${ }^{3}$, Kevin Robbins ${ }^{2}$, Andrew Fowler ${ }^{3}$ and Laurie Lee 2 $^{2^{*}}$

\begin{abstract}
Background: Patients with asthma uncontrolled on inhaled corticosteroids may benefit from umeclidinium (UMEC), a long-acting muscarinic antagonist.

Methods: This Phase Ilb, double-blind study included patients with reversible, uncontrolled/partially-controlled asthma for $\geq 6$ months, receiving $\geq 100 \mathrm{mcg} /$ day fluticasone propionate (or equivalent) for $\geq 12$ weeks. Following a 2-week run-in on open-label fluticasone furoate (FF) $100 \mathrm{mcg}$, patients were randomised (1:1:1) to receive UMEC $31.25 \mathrm{mcg}$, UMEC $62.5 \mathrm{mcg}$ or placebo on top of FF $100 \mathrm{mcg}$ once-daily for 24 weeks. As-needed salbutamol was provided. Primary and secondary endpoints were change from baseline in clinic trough forced expiratory volume in $1 \mathrm{~s}\left(\mathrm{FEV}_{1}\right)$ and clinic $\mathrm{FEV}_{1} 3 \mathrm{~h}$ post-dose, respectively, at Week 24. Other endpoints included change from baseline in home daily spirometry (trough $\mathrm{FEV}_{1}$, evening $\mathrm{FEV}_{1}$, morning [pre-dose] and evening peak expiratory flow) over 24 weeks. Safety was assessed throughout the study.

Results: The intent-to-treat population comprised 421 patients (UMEC 31.25 mcg: $n=139$, UMEC 62.5 mcg: $n=139$, placebo: $n=143$ ). UMEC $31.25 \mathrm{mcg}$ and $62.5 \mathrm{mcg}$ demonstrated significantly greater improvements from baseline in clinic trough $\mathrm{FEV}_{1}$ at Week 24 (difference [95\% Cl]: $0.176 \mathrm{~L}[0.092,0.260 ; p<0.001]$ and $0.184 \mathrm{~L}$ $[0.101,0.268 ; p<0.001]$, respectively), clinic FEV 3 h post-dose at Week $24(0.190 \mathrm{~L}[0.100,0.279 ; p<0.001]$ and $0.198 \mathrm{~L}[0.109,0.287 ; p<0.001]$, respectively) and mean change from baseline in daily home spirometry over 24 weeks versus placebo. No new safety signals were identified.

Conclusions: UMEC is a highly effective bronchodilator that leads to improved lung function when administered as a single bronchodilator on top of FF in subjects with fully reversible, uncontrolled/partiallycontrolled moderate asthma. These data support a favourable benefit/risk profile for UMEC (31.25 mcg and $62.5 \mathrm{mcg})$.
\end{abstract}

Trial registration: GSK study ID: 205832; Clinicaltrials.gov ID: NCT03012061.

Keywords: Asthma, Forced expiratory volume in $1 \mathrm{~s}$, Inhaled corticosteroid, Long-acting muscarinic antagonist, Umeclidinium

\footnotetext{
* Correspondence: laurie.myers.lee@gmail.com

Steven Pascoe, Robert Nathan, Ronald Dahl and Laurie Lee at time of study.

${ }^{2}$ GSK, Upper Providence, PA, USA

Full list of author information is available at the end of the article
}

C C The Author(s). 2020 Open Access This article is licensed under a Creative Commons Attribution 4.0 International License, which permits use, sharing, adaptation, distribution and reproduction in any medium or format, as long as you give appropriate credit to the original author(s) and the source, provide a link to the Creative Commons licence, and indicate if changes were made. The images or other third party material in this article are included in the article's Creative Commons licence, unless indicated otherwise in a credit line to the material. If material is not included in the article's Creative Commons licence and your intended use is not permitted by statutory regulation or exceeds the permitted use, you will need to obtain permission directly from the copyright holder. To view a copy of this licence, visit http://creativecommons.org/licenses/by/4.0/ The Creative Commons Public Domain Dedication waiver (http://creativecommons.org/publicdomain/zero/1.0/) applies to the data made available in this article, unless otherwise stated in a credit line to the data. 


\section{Background}

Asthma, a common chronic condition, can occur at all ages [1-3]. In 2015, the prevalence of asthma was 358.2 million worldwide, reflecting an increase of $12.6 \%$ from 1990 [1]. Asthma is associated with respiratory symptoms and variable airflow limitation, and patients can be prone to exacerbations that may require treatment with systemic corticosteroids, urgent care visits or hospitalisations [2]. The Global Initiative for Asthma (GINA) 2019 strategy report recommends inhaled corticosteroids (ICS) as a controller treatment for patients with asthma [2]. ICS treatment can decrease inflammation, especially where there is evidence of a T-helper Type 2 allergic asthma phenotype [4]. Despite the availability of ICS treatment, which is often associated with improvements in symptom control, lung function and number of exacerbations [2], many patients remain uncontrolled; in 2010, 53.5\% of treated patients with asthma in European countries were assessed as having not well-controlled asthma by the Asthma Control Test (trademark of QualityMetric Incorporated) [5].

Patients whose asthma symptoms remain uncontrolled with a history of exacerbations on ICS and a long-acting $\beta_{2}$-agonist (LABA) may benefit from the addition of a long-acting muscarinic antagonist (LAMA) [2]. For example, tiotropium, a LAMA that has been approved as a long-term maintenance treatment for asthma in the United States (US) [6], the European Union [7] and Japan, has been associated with improvements in lung function and other clinical outcomes in patients with poorly controlled asthma despite receiving ICS or ICS/LABA therapy [8-10], with a similar magnitude of effect from adding LAMA to ICS as adding LABA to ICS $[8,11,12]$.

The benefits of the LAMA umeclidinium (UMEC) on lung function are well established in chronic obstructive pulmonary disease (COPD) [13], and have also been described in patients with asthma and in those with features of both asthma and COPD [14, 15]. For example, improvements in trough forced expiratory volume in $1 \mathrm{~s}$ $\left(\mathrm{FEV}_{1}\right)$ and pre-dose peak expiratory flow (PEF) have been reported for UMEC in combination with the ICS fluticasone furoate (FF) versus FF alone [14, 15]. To characterise the effects of UMEC in asthma and its longevity, this 24-week superiority study was conducted to evaluate the efficacy, safety and tolerability of once-daily UMEC $31.25 \mathrm{mcg}$ or $62.5 \mathrm{mcg}$ versus placebo in patients with asthma receiving FF $100 \mathrm{mcg}$ who had previously been receiving ICS with or without a long-acting bronchodilator. UMEC $62.5 \mathrm{mcg}$ was chosen as the upper dose based on findings from a previous study in which clinically meaningful improvements in lung function were reported versus FF alone [15]. The $31.25 \mathrm{mcg}$ dose was selected for our study because the lowest UMEC dose used in the previous study $(15.6 \mathrm{mcg})$ showed only modest improvements in lung function. Patients were required to have fully reversible asthma, with a postbronchodilator $\mathrm{FEV}_{1} /$ forced vital capacity (FVC) $\geq 0.7$ [2], in order to exclude patients with fixed airway obstruction, in whom UMEC dose selection has previously been explored [15]. This study forms part of a clinical development programme for a closed triple ICS/LAMA/LABA therapy for asthma and will be used to help inform the choice of UMEC dose in the target population for FF/UMEC/VI. While the main focus of the study was to assess efficacy of UMEC on pulmonary function as measured by clinic and home spirometry, the Evaluating Respiratory Symptoms (E-RS) questionnaire [16, 17] was also included to evaluate its utility in patients with asthma with milder disease than have been assessed in previous studies $[14,15]$. The E-RS is a respiratory symptom score developed and validated for use as part of the EXAcerbations of COPD (EXACT) instrument, a patient-reported outcome (PRO) measure for COPD, and subsequently evaluated in patients with features of both asthma and COPD [18].

\section{Materials and methods Study design}

This 24-week, Phase IIb, randomised, double-blind, placebo-controlled, parallel-group study (GSK study ID: 205832; Clinicaltrials.gov ID: NCT03012061) was conducted in Canada, Poland, Romania, Russian Federation and the US and compared the efficacy and safety of two doses of UMEC with placebo in patients with asthma. The study took place between January 2017 and May 2018. Following a pre-screening visit (Visit 0), asthma treatments were adjusted so that patients received ICS monotherapy without LABA or LAMA. At screening (Visit 1), patients entered a 2-week run-in period where their usual asthma therapy was stopped and replaced with open-label FF $100 \mathrm{mcg}$ administered once daily via an ELLIPTA dry powder inhaler (DPI). Patients were then randomised (1:1:1) to receive UMEC $31.25 \mathrm{mcg}$, UMEC $62.5 \mathrm{mcg}$ or placebo once daily (morning [AM]) for 24 weeks, administered via a separate ELLIPTA DPI, while remaining on FF $100 \mathrm{mcg}$ (Fig. 1a). Following randomisation (Visit 2, Day 1), patients attended visits at Week 4 (Visit 3), Week 12 (Visit 4) and Week 24 (Visit 5), followed by a safety follow-up (FU) visit approximately 7 days after Visit 5. Patients who prematurely discontinued study treatment were encouraged to continue in the study for collection of post-treatment data, and patients who withdrew from the study at any time before completing a visit at Week 24 were encouraged to attend an early withdrawal visit. The study was divided into 4 study periods: screening/run-in (screening date to randomisation or treatment start date, if the first treatment dose was taken after the randomisation visit); on treatment (treatment start date to stop date plus 1 day); post treatment 
A.

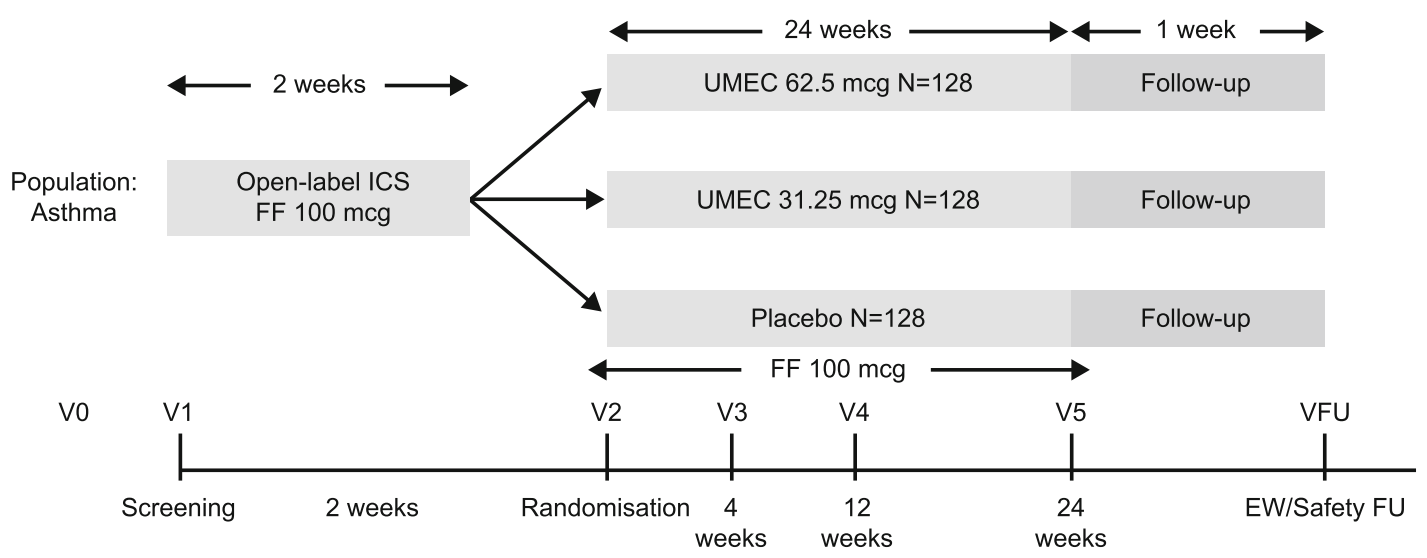

B.

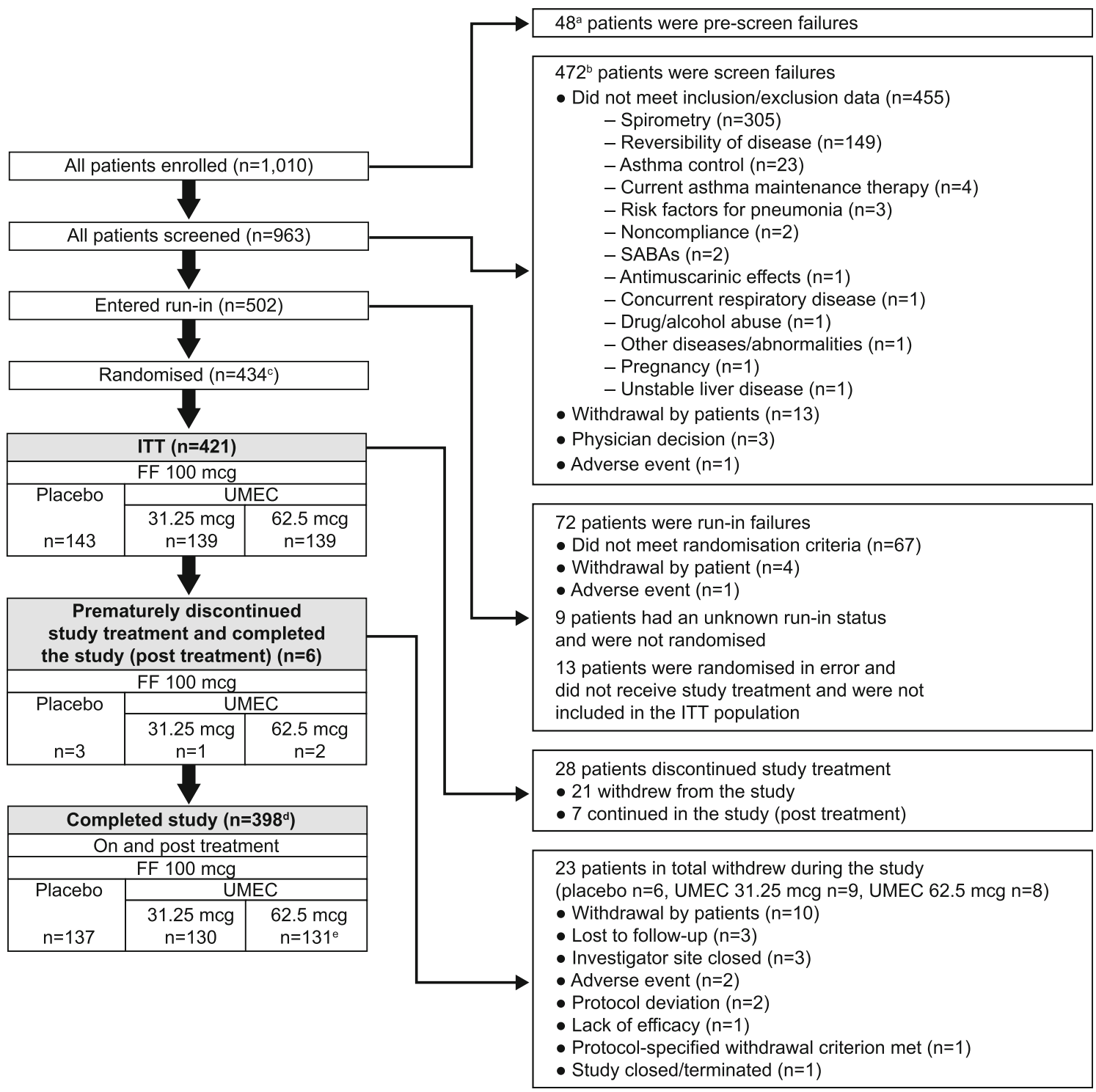

Fig. 1 (See legend on next page.) 
(See figure on previous page.)

Fig. 1 (a) Study design and (b) patient disposition. ${ }^{a}$ One patient failed pre-screening and entered screening, and was counted as both a prescreen failure and in the all patients screened population. ${ }^{b}$ Eleven patients failed screening and entered the run-in period, and were counted as

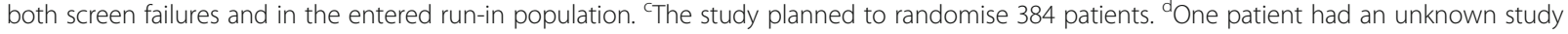
completion status. ${ }^{~}$ Patient 954 in the UMEC $62.5 \mathrm{mcg}$ group discontinued study treatment the day prior to Visit 5 (Week 24) and was not dosed at that clinic visit. However, this patient was not reported as prematurely discontinuing study treatment in the eCRF and was counted in the completed study population. On treatment was defined as study treatment start date day (inclusive) to study treatment stop date +1 (inclusive). Post treatment was defined as study treatment stop date +1 day (exclusive) to Visit 5/EW Visit date (as applicable) (inclusive). The all patients enrolled population included all patients for whom a record exists in the database. The all patients screened population included all patients who completed $\geq 1$ screening procedure. The randomised population included all patients who were randomised. The ITT population included all patients who were randomised, excluding those who were randomised in error and did not receive study treatment. AE, adverse event; eCRF, electronic Case Report Form; EW, early withdrawal; FF, fluticasone furoate; FU, follow-up; ICS, inhaled corticosteroid; ITT, intent-to-treat, SABA, short-acting $\beta_{2}$-agonist; UMEC, umeclidinium; V, visit

(treatment stop date plus 1 day to Visit 5/Early Withdrawal, visit inclusive for patients who continued in the study after discontinuing study treatment); and post study (any time after Visit 5/Early Withdrawal, all patients had a safety follow up 7 days after Visit 5/Early Withdrawal).

Salbutamol was provided to patients as a metered dose inhaler (MDI) for use during the study as a rescue medication. Salbutamol was withheld for $\geq 6 \mathrm{~h}$ prior to Visits 2-5/Early Withdrawal Visit (as applicable) and home spirometry was to be performed prior to any salbutamol use. Additional asthma medications for exacerbations were permitted at the discretion of the investigator. A summary of permitted and prohibited medications is included in Supplementary Table 1.

Patients were assigned to treatment using a randomisation schedule generated with a validated computerised system using RAMOS NG software. Double-blinding was ensured by administering study drug and placebo using matched ELLIPTA DPIs.

\section{Patient sample Inclusion and exclusion criteria}

At Visit 0 (pre-screening), patients were required to be $\geq 18$ years of age with a diagnosis of asthma (as defined by National Institutes of Health [3]) for $\geq 6$ months, receiving continuous therapy with ICS $\geq 100 \mathrm{mcg} /$ day fluticasone propionate (or equivalent) \pm LABA or LAMA for $\geq 12$ weeks with no change in asthma therapy for the previous 4 weeks and able to withhold rescue medication for $\geq 6 \mathrm{~h}$ before each clinic visit.

At screening, patients were required to have an Asthma Control Questionnaire (ACQ)-6 score $>0.75$, and therefore considered to have either partially controlled (ACQ-6 score $>0.75$ and $<1.5$ ) or uncontrolled asthma (ACQ-6 score $\geq 1.5$ ). Patients were also required to have a pre-bronchodilator $\mathrm{AM} \mathrm{FEV}_{1} \leq 90 \%$ predicted, AND a post-bronchodilator $\mathrm{FEV}_{1} / \mathrm{FVC} \geq 0.7$ and evidence of reversibility to salbutamol $(\geq 12 \%$ and $\geq 200 \mathrm{~mL}$ increase in $\mathrm{FEV}_{1}$ 20-60 min following inhalation), referred to here as fully reversible asthma.
Patients who had x-ray-documented pneumonia, a severe asthma exacerbation within 12 weeks prior to screening, pneumonia risk factors such as immune suppression or neurological disorders affecting control of the upper airway at screening were excluded, as were those who had evidence of a concurrent respiratory disease (including emphysema or COPD) or current and clinically significant disease of the major body systems and uncontrolled haematological abnormalities. Those with current unstable liver disease, clinically significant electrocardiogram abnormalities, current unstable and life-threatening cardiac disease, conditions that may be affected by antimuscarinic use, or cancer within the previous 5 years were also excluded. Current and former smokers with a history of $\geq 10$ pack years and inhaled tobacco use in the previous 12 months were also excluded, in order to omit patients who may have a COPD component.

\section{Randomisation criteria}

Patients were eligible for randomisation if they continued to have an ACQ- 6 score $>0.75$ and an AM prebronchodilator $\mathrm{FEV}_{1} \leq 90 \%$ predicted at Visit 2, were compliant with the electronic diary (eDiary) on $\geq 4 / 7$ final days of the run-in period and had no change in asthma therapy during the run-in period. Patients who experienced a moderate/severe asthma exacerbation or a respiratory infection during the run-in period were not eligible to be randomised.

\section{Endpoints}

The primary efficacy endpoint was mean change from baseline (CFB) in clinic trough $\mathrm{FEV}_{1}$ at Week 24. The secondary efficacy endpoint was mean CFB in clinic $\mathrm{FEV}_{1} 3 \mathrm{~h}$ post dose at Week 24. Other efficacy endpoints included mean $\mathrm{CFB}$ in home spirometry readings (trough $\mathrm{FEV}_{1}$, evening $[\mathrm{PM}] \mathrm{FEV}_{1}$, AM PEF and PM $\mathrm{PEF}$ ) and mean rescue medication use (puffs/day) over the 24-week period, mean CFB in PROs (St George's Respiratory Questionnaire [SGRQ] total and domain scores, Asthma Quality of Life Questionnaire [AQLQ] 
total score, ACQ-5 total score and E-RS total score) and percentage of patients meeting a responder threshold for CFB in SGRQ total score ( $\geq 4$ points improvement [decrease]) [19], AQLQ total score $(\geq 0.5$ points improvement [increase]) [20] and ACQ-5 total score ( $\geq 0.5$ points improvement [decrease]) [21], annualised rate of moderate/severe and severe asthma exacerbations and time to first moderate/severe and severe exacerbation. Safety endpoints included incidence of adverse events (AEs), serious AEs (SAEs) and AEs of special interest (AESIs) as well as electrocardiogram measurements and vital signs throughout the study.

\section{Assessments}

$\mathrm{FEV}_{1}$ (pre- and post-dose) and SGRQ, AQLQ and ACQ-5 scores were assessed during clinic visits. An eDiary was used to record AM (pre-study treatment or pre-runin treatment, as applicable) and PM (pre-rescue bronchodilator) PEF. In the morning, PEF was captured upon waking at 6-11 AM. Home trough and $\mathrm{PM} \mathrm{FEV}_{1}$, rescue medication use and E-RS total score were also recorded using the eDiary. The E-RS total score consisted of the 11 respiratory symptom items from the 14-item EXACT: COPD PRO measure (score: $0-40$, minimal clinically important difference $[\mathrm{MCID}]: \geq-2$ points) $[16,17]$. Nighttime wakening, asthma symptoms and physical activity were also recorded, though not analysed as endpoints. Exacerbations, emergency department visits and hospitalisations were reported by patients using a medical problems/ medications taken worksheet. A moderate exacerbation was defined as a deterioration in asthma symptoms, a deterioration in lung function or increased rescue bronchodilator use lasting $\geq 2$ days that did not require $\geq 3$ days of systemic corticosteroid use and/or hospitalisation [22, 23]. A severe exacerbation was defined as a deterioration of asthma that required either systemic corticosteroids for $\geq 3$ days or hospitalisation or an emergency department visit due to asthma that required systemic corticosteroids [22]. Exacerbations that occurred within 7 days of the previous exacerbation were treated as a continuation of the same exacerbation.

\section{Statistical analyses}

With a sample size of 115 patients per treatment group, the study had $80 \%$ power to detect a statistically significant difference in trough $\mathrm{FEV}_{1}$ at Week 24 at the 2 -sided $5 \%$ level, assuming a true treatment difference of $130 \mathrm{~mL}$ and standard deviation (SD) of $350 \mathrm{~mL}[8,15]$. Randomisation of 128 patients per treatment group was planned to allow $10 \%$ missing data. The intent-to-treat (ITT) population, which included all patients randomised except those randomised in error and not treated, was used for the efficacy and safety analyses.
This was a superiority study designed to demonstrate the benefit of UMEC 31.25 and $62.5 \mathrm{mcg}$ versus placebo in patients on background therapy of FF $100 \mathrm{mcg}$. Multiplicity across the primary treatment comparisons for the primary endpoint was controlled using a step-down procedure based on a statistical hierarchy, firstly testing UMEC $62.5 \mathrm{mcg}$ versus placebo, and then testing UMEC $31.25 \mathrm{mcg}$ versus placebo. For the secondary and other endpoints, both UMEC doses versus placebo were also compared without adjustment for multiplicity. In addition, UMEC $31.25 \mathrm{mcg}$ was compared with UMEC $62.5 \mathrm{mcg}$ in an exploratory manner for all analyses. No $p$-values are reported for these endpoints and we instead include treatment estimates and 95\% confidence intervals (CI).

The primary efficacy endpoint was analysed using a mixed model repeated measures (MMRM) that included covariates of treatment group, sex, region, visit, age, and baseline value, and interactions of baseline value by visit and treatment group by visit. The secondary endpoint was evaluated using an analysis of covariance adjusting for covariates as per the primary efficacy analysis above, excluding visit and the by visit interaction terms. Home spirometry, rescue medication use and E-RS total score were analysed by deriving mean values over 4-weekly incremental periods from Week 1 to Week 24. Additionally, mean weekly values over Weeks $1-8$ were derived for trough $\mathrm{FEV}_{1}$. A minimum of $50 \%$ of data was required for a period to derive an analysis value. An MMRM model adjusted for the covariates treatment, age, sex, region, baseline value, period, treatment by period interaction and baseline value by period interaction was used. An estimate over Weeks 1-24 was obtained for these endpoints from the MMRM analysis. SGRQ total and domain scores and total scores for AQLQ and ACQ-5 were analysed using a MMRM model similar to that used for the primary endpoint but adapted for the endpoint being analysed. Responder analyses for the PRO measures were conducted using a generalised linear model for binary outcome measures, appropriately adjusted for covariates as above. Exacerbation rates were analysed using a generalised linear model assuming a negative binomial distribution with log (time on study) as an offset variable, and time to first exacerbation was analysed using a Cox's proportional hazards model. Both models were appropriately adjusted for covariates as above. Selected safety endpoints (systolic blood pressure, diastolic blood pressure, pulse rate, QT interval corrected for pulse rate by Fridericia's formula, PR interval) were analysed using a similar MMRM model to the primary efficacy analysis, adapted for the endpoint being analysed.

A tipping point and a jump to reference sensitivity analysis were performed on mean CFB in clinic trough $\mathrm{FEV}_{1}$ at Week 24, based on the ITT population. These 
analyses explored the impact of missing data by multiply imputing the unobserved data based on different assumptions in each treatment group. For each, imputation considered the same covariates in the model as the primary efficacy analysis modelled at each visit. The tipping point analysis assumed a range of scenarios for participants who withdrew, which varied independently for the two UMEC treatment groups and the placebo group. Results were used to explore the conditions under which the significant difference between UMEC $62.5 \mathrm{mcg}$ versus placebo and UMEC $31.25 \mathrm{mcg}$ versus placebo no longer held true. The jump to reference analysis assumed patients in the UMEC groups who withdrew from the study would have provided data similar to that observed in the placebo group. The SAS 9.4 package was used for all statistical analyses.

For eDiary endpoints (home spirometry, rescue medication use, E-RS total score), the baseline value was the final 14 days of the run-in period prior to initiating study treatment. A minimum of 7 days data was required to derive a baseline value. Baseline for PRO scores was the score determined at randomisation (Visit 1). For clinic $\mathrm{FEV}_{1}$, the baseline measurement was the last measurement prior to the start of randomised treatment.

\section{Results}

\section{Patients}

Of the 1,010 patients enrolled, 963 were screened, 434 were randomised and 398 completed the study. The ITT population included 421 patients (UMEC $31.25 \mathrm{mcg}$ : $n=139$, UMEC $62.5 \mathrm{mcg}: n=139$, placebo: $n=143$ ) as 13 patients were randomised in error and were not treated. Of those screened, 472 ( $47 \%$ of the enrolled population) patients failed screening, mainly due to failure to meet the inclusion/exclusion criteria $(n=455$ [96\%]), particularly the spirometry and/or reversibility criteria (Fig. 1b). Of the enrolled patients, $7 \%$ were considered run-in failures, mainly due to not meeting the randomisation criteria (93\%) of compliance with eDiary reporting (35\%) and not meeting the $\mathrm{FEV}_{1} \%$ predicted criterion (33\%).

Patients had a mean (SD) age of 48.8 (14.6) years, most (71\%) were female, had never smoked (92\%), and were inadequately controlled as shown by PRO scores (Table 1). The mean (SD) age of asthma onset and duration was 33.8 (17.23) and 14.8 (13.63) years, respectively (Table 1). The study population had inadequately controlled asthma at baseline, with mean (SD) total scores for ACQ-6 and SGRQ of 1.7 (0.5) and 36 (17), respectively, and a mean (SD) baseline use of rescue salbutamol of 1.2 (1.4) puffs per day. Mean (SD) reversibility to salbutamol was $28.3 \%$ (19.4) and patients displayed moderate pre-bronchodilator airflow obstruction with mean (SD) $\mathrm{FEV}_{1} \%$ predicted of $68.6 \%$ (11.7). Fifteen percent of patients experienced one or more severe asthma exacerbations in the prior year (Table 1). All baseline demographic parameters were similar across treatment groups. Minor differences in clinical characteristics (Table 1) and regional demographics were noted that were not considered to influence the study conclusions (Supplementary Table 2).

\section{Clinic FEV 1}

At Week 24, all treatments administered with FF, including placebo, were associated with increases in the least squares (LS) mean (95\% CI) CFB in clinic trough $\mathrm{FEV}_{1}$ (placebo: $0.129 \mathrm{~L}$ [0.070, 0.187], UMEC $31.25 \mathrm{mcg}$ : 0.305 L [0.245, 0.364], UMEC 62.5 mcg: 0.313 L [0.254, 0.372]; Fig. 2a) and clinic $\mathrm{FEV}_{1} 3 \mathrm{~h}$ post dose (placebo: 0.177 L [0.114, 0.239], UMEC 31.25 mcg: 0.366 L [0.302, 0.430], UMEC 62.5 mcg: 0.374 L [0.311, 0.438]; Fig. 2b). For trough $\mathrm{FEV}_{1}$, the increase versus placebo was significantly greater for both UMEC doses at Week 24, with a difference $(95 \% \mathrm{CI})$ of $0.176 \mathrm{~L}(0.092,0.260 ; p<0.001)$ for UMEC $31.25 \mathrm{mcg}$ and $0.184 \mathrm{~L}(0.101,0.268$; $p<0.001$ ) for UMEC $62.5 \mathrm{mcg}$ (Fig. 2a). For both doses of UMEC versus placebo, the sensitivity analyses demonstrated that the primary efficacy outcome was robust. These findings were supported by the CFB in clinic $\mathrm{FEV}_{1} 3 \mathrm{~h}$ post dose at Week 24, which was significantly greater with UMEC $31.25 \mathrm{mcg}$ and $62.5 \mathrm{mcg}$ compared with placebo, with differences $(95 \% \mathrm{CI})$ of $0.190 \mathrm{~L}(0.100,0.279 ; p<0.001)$ and $0.198 \mathrm{~L}$ (0.109, 0.287; $p<0.001)$, respectively (Fig. 2b). CFB in clinic trough $\mathrm{FEV}_{1}$ was also significantly greater at Weeks 4 and 12 for both UMEC $31.25 \mathrm{mcg}$ and $62.5 \mathrm{mcg}$ versus placebo (Fig. 2c).

\section{Other efficacy endpoints}

Over the 24-week treatment period (Weeks 1-24), increases in LS mean CFB in home trough $\mathrm{FEV}_{1}$ were observed with UMEC 31.25 mcg (0.036 L, 95\% CI: - 0.012, $0.084)$ and UMEC $62.5 \mathrm{mcg}(0.061 \mathrm{~L}, 95 \% \mathrm{CI}: 0.013$, 0.109 ) but not with placebo, which was associated with a small $\mathrm{FEV}_{1}$ reduction $(-0.038 \mathrm{~L}, 95 \% \mathrm{CI}:-0.085$, 0.010). Treatment differences versus placebo were $0.074 \mathrm{~L}(0.006,0.141 ; p=0.033)$ for UMEC $31.25 \mathrm{mcg}$ and $0.098 \mathrm{~L}(0.031,0.166 ; p=0.004)$ for UMEC $62.5 \mathrm{mcg}$ (Table 2).

When home trough $\mathrm{FEV}_{1}$ measurements were considered over weekly intervals during Weeks $1-8$, there were significant increases from Week 1 with both doses of UMEC versus placebo (Fig. 3a).

Over 24 weeks, considering weekly intervals, UMEC $62.5 \mathrm{mcg}$ showed statistically significant improvements versus placebo for home trough $\mathrm{FEV}_{1}$ during each period. UMEC $31.25 \mathrm{mcg}$ also showed improvements versus placebo over the 24-week period; however, they were smaller than for UMEC $62.5 \mathrm{mcg}$ and only met statistical significance $(p<0.05)$ for three of the six 
Table 1 Baseline demographics and clinical characteristics at screening and randomisation (ITT population)

\begin{tabular}{|c|c|c|c|c|}
\hline & Placebo $(N=143)$ & UMEC $31.25 \mathrm{mcg}(N=139)$ & UMEC $62.5 \mathrm{mcg}(\mathrm{N}=139)$ & Total $(N=421)$ \\
\hline Age $^{*}$, years & $49.3(13.93)$ & $48.7(15.83)$ & $48.5(14.21)$ & $48.8(14.64)$ \\
\hline Female, n (\%) & $106(74)$ & $94(68)$ & $98(71)$ & $298(71)$ \\
\hline Race: White, n (\%) & $131(92)$ & $127(91)$ & $129(93)$ & $387(92)$ \\
\hline $\mathrm{BMI}, \mathrm{kg} / \mathrm{m}^{2}$ & $29.89(7.31)$ & $29.40(7.52)$ & $29.02(7.68)$ & $29.44(7.49)$ \\
\hline \multicolumn{5}{|l|}{ Smoking status, n (\%) } \\
\hline Never smoked & $127(89)$ & $132(95)$ & $129(93)$ & $388(92)$ \\
\hline Former smoker & $16(11)$ & $7(5)$ & $10(7)$ & $33(8)$ \\
\hline Number of pack years, mean (SD) & $4.05(2.74)$ & $4.14(2.70)$ & $1.85(1.79)$ & $3.40(2.62)$ \\
\hline Duration of asthma, years & $15.06(14.40)$ & $13.82(12.92)$ & $15.61(13.54)$ & $14.83(13.63)$ \\
\hline Age of onset of asthma ${ }^{\dagger}$, years & $33.9(16.71)$ & $34.7(17.90)$ & $32.6(17.13)$ & $33.8(17.23)$ \\
\hline \multirow[t]{2}{*}{ Pre-bronchodilator $\mathrm{FEV}_{1}, \mathrm{~L}$} & $n=143$ & $n=137$ & $n=139$ & $n=419$ \\
\hline & $2.11(0.71)$ & $2.18(0.72)$ & $2.15(0.60)$ & $2.14(0.68)$ \\
\hline \multirow[t]{2}{*}{ Pre-bronchodilator predicted $\mathrm{FEV}_{1}, \%$} & $n=143$ & $n=137$ & $n=139$ & $n=419$ \\
\hline & $67.90(12.09)$ & $68.85(12.00)$ & $69.11(11.12)$ & $68.61(11.72)$ \\
\hline \multirow[t]{2}{*}{ Pre-bronchodilator $\mathrm{FEV}_{1} / \mathrm{FVC}$, ratio } & $n=143$ & $n=137$ & $n=139$ & $n=419$ \\
\hline & $0.70(0.08)$ & $0.70(0.09)$ & $0.72(0.09)$ & $0.71(0.09)$ \\
\hline \multirow[t]{2}{*}{ Reversibility, \% } & $n=142$ & $n=137$ & $n=138$ & $n=417$ \\
\hline & $25.97(15.89)$ & $28.21(18.64)$ & $30.75(22.84)$ & $28.29(19.36)$ \\
\hline SGRQ total score" & $36.96(17.45)$ & $35.56(15.75)$ & $36.30(18.06)$ & $36.28(17.09)$ \\
\hline AQLQ total score & $5.03(0.93)$ & $5.10(0.87)$ & $5.14(0.80)$ & $5.09(0.87)$ \\
\hline ACQ-6 score" & $1.70(0.55)$ & $1.69(0.54)$ & $1.59(0.53)$ & $1.66(0.54)$ \\
\hline \multicolumn{5}{|l|}{ ACQ-6 control category ${ }^{\Uparrow \S}, \mathrm{n}(\%)$} \\
\hline Partially controlled & $51(36)$ & $53(38)$ & $60(43)$ & $164(39)$ \\
\hline Inadequately controlled & $92(64)$ & $85(62)$ & $79(57)$ & $256(61)$ \\
\hline E-RS total score ${ }^{ \pm}$ & $7.58(5.58)$ & $7.20(5.11)$ & $7.44(5.52)$ & $7.41(5.40)$ \\
\hline Rescue medication use ${ }^{ \pm}$, puffs/day & $1.30(1.46)$ & $1.30(1.61)$ & $1.00(1.21)$ & $1.20(1.44)$ \\
\hline \multicolumn{5}{|l|}{$\begin{array}{l}\text { Number of severe exacerbations in the } \\
12 \text { months prior to screening, } n(\%)\end{array}$} \\
\hline 0 & $123(86)$ & $108(78)$ & $128(92)$ & 359 (85) \\
\hline 1 & $16(11)$ & $22(16)$ & $9(6)$ & $47(11)$ \\
\hline$\geq 2$ & $4(3)$ & $9(6)$ & $2(1)$ & $15(4)$ \\
\hline
\end{tabular}

Data are mean (SD) unless otherwise stated

${ }^{*}$ Age is derived using the date of the pre-screening visit. Only year of birth is collected. Day and month of birth are imputed as 30 June. ${ }^{\dagger}$ Calculated based on age and duration of asthma at pre-screening. "Baseline value was defined as score recorded at the Randomisation visit (Visit 2/Day 1).

${ }^{5} \mathrm{ACQ}-6$ score 0.75 to <1.5: partially controlled; ACQ-6 score $\geq 1.5$ : inadequately controlled. ${ }^{ \pm}$Baseline value was defined as the mean over the last 14 days during the run-in period prior to study treatment start date (Randomisation).

ACQ-6 Asthma Control Questionnaire-6, AQLQ Asthma Quality of Life Questionnaire, BMI body mass index, E-RS total score Evaluating Respiratory Symptoms, FEV 1 forced expiratory volume in $1 \mathrm{~s}$, FVC forced vital capacity, ITT intent-to-treat, SD standard deviation, SGRQ St George's Respiratory Questionnaire, UMEC umeclidinium

periods. Placebo showed a decline up until Week 12 (Table 2, Fig. 3b). Greater CFB in home trough FEV over the Week 21-24 period was observed with both UMEC doses versus placebo, with treatment differences $(95 \% \mathrm{CI})$ of $0.071 \mathrm{~L} \quad(-0.011,0.152 ; p=0.089)$ for UMEC $31.25 \mathrm{mcg}$ and $0.118(0.037,0.199 ; p=0.004)$ for UMEC 62.5 mcg (Table 2).

Significantly greater improvements from baseline in home PM FEV ${ }_{1}$, AM pre-dose PEF and PM PEF with both doses of UMEC versus placebo were also seen over the 24-week treatment period, with a decline from the baseline in placebo for all three measures (Weeks 1-24; Supplementary Table 3). For AM PEF, significant improvements with both UMEC doses versus placebo occurred early (by Weeks 1-4) and were maintained over the treatment period (Fig. 3c), with similar results for PM PEF (data not shown).

At Week 24, reduced rescue medication use was seen in all treatment groups, with no significant differences between either of the UMEC doses and placebo (Supplementary Table 4). 
A.

UMEC $62.5 \mathrm{mcg}$ vs placebo: $0.184 \mathrm{~L}$

UMEC $31.25 \mathrm{mcg}$ vs placebo: $0.176 \mathrm{~L}$

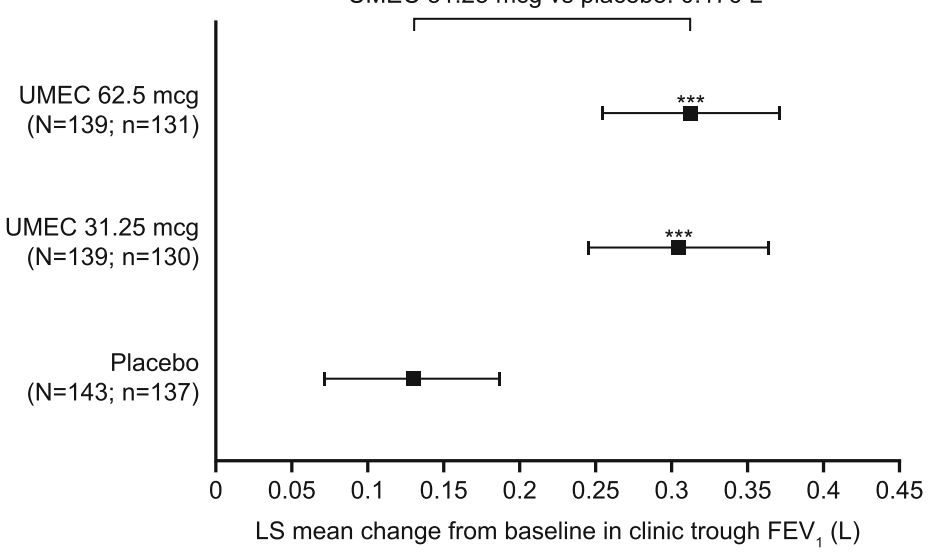

B.

UMEC $62.5 \mathrm{mcg}$ vs placebo: $0.198 \mathrm{~L}$

$\longrightarrow$

UMEC $31.25 \mathrm{mcg}$ vs placebo: $0.190 \mathrm{~L}$

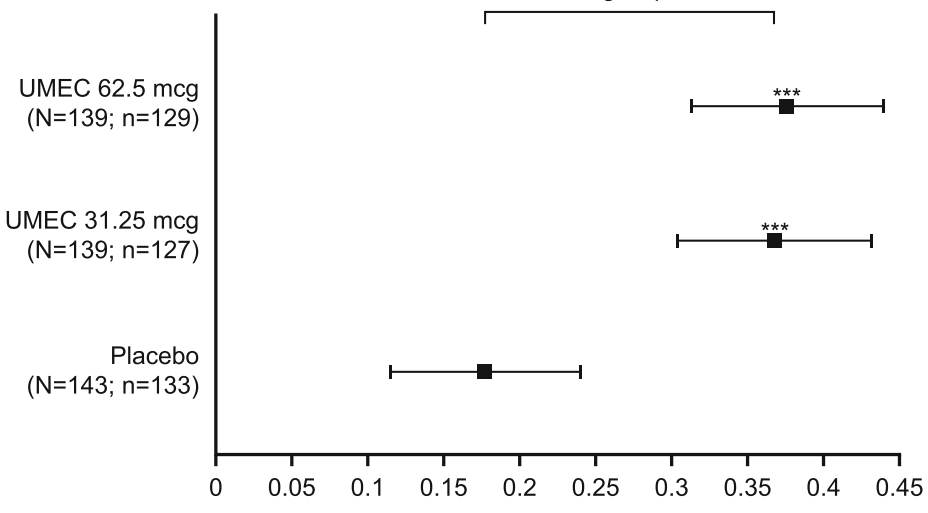

LS mean change from baseline in clinic FEV $(\mathrm{L})$

at 3 hours post dose

c.

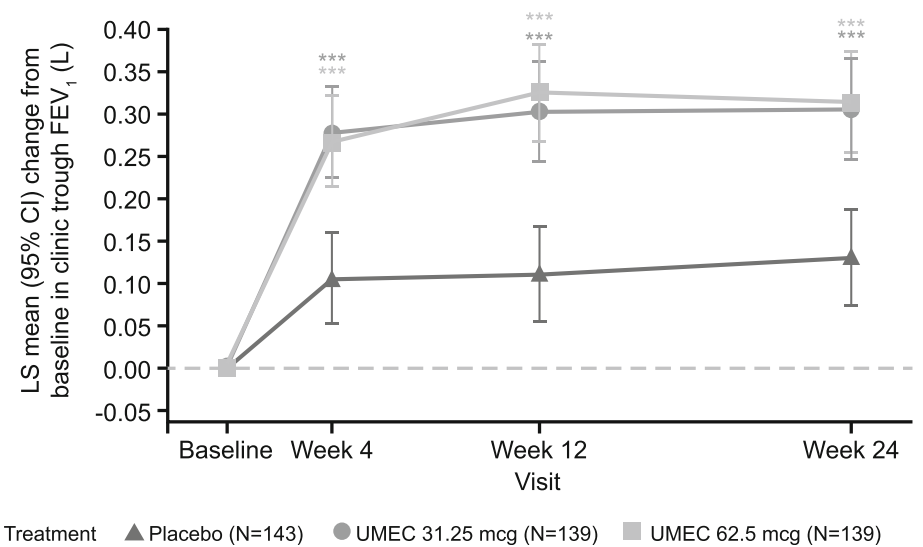

Fig. 2 (See legend on next page.) 
(See figure on previous page.)

Fig. 2 LS mean change from baseline in clinic spirometry measures (ITT population). LS mean (95\% CI) change from baseline in clinic (a) trough FEV $_{1}$ at Week 24, (b) FEV 1 (L) at 3 h post dose at Week 24 and (c) trough FEV 1 at Weeks 4, 12 and 24 (ITT population). Error bars represent 95\% $\mathrm{Cl}_{\text {I }}$ ${ }^{* * *} p<0.001$, treatment difference from placebo. $\mathrm{Cl}$, confidence interval; $\mathrm{FEV}_{1}$, forced expiratory volume in $1 \mathrm{~s}$; ITT, intent-to-treat; LS, least squares; UMEC, umeclidinium; N, ITT population; n, number of participants with analysable data at Week 24

\section{PRO endpoints}

For all PRO measures (SGRQ total and domain scores, AQLQ total score, ACQ-5 total score and E-RS total score), improvements from baseline were seen in all three treatment groups at Week 24. The changes were greater than the MCIDs for SGRQ total and domain scores, AQLQ total score and ACQ-5 total score [19-21, 24]; the E-RS does not have an accepted MCID in asthma, nevertheless it was reduced by at least 2 units in both UMEC groups
(Supplementary Table 4). With the exception of SGRQ impact score for UMEC $31.25 \mathrm{mcg}$ and AQLQ total score for UMEC $62.5 \mathrm{mcg}$, patients treated with either dose of UMEC consistently showed numerically greater improvements in PRO scores at Week 24 compared with those who were treated with placebo, although differences were not significant (Supplementary Table 4).

For E-RS total score, statistically significant improvements from baseline with UMEC $31.25 \mathrm{mcg}$ and

Table 2 Effect of UMEC 31.25 and 62.5 mcg versus placebo on home trough FEV

\begin{tabular}{|c|c|c|c|c|}
\hline & Time point & $\begin{array}{l}\text { Placebo } \\
(N=143)\end{array}$ & $\begin{array}{l}\text { UMEC } 31.25 \mathrm{mcg} \\
(N=139)\end{array}$ & $\begin{array}{l}\text { UMEC } 62.5 \mathrm{mcg} \\
(\mathrm{N}=139)\end{array}$ \\
\hline $\mathrm{n}$ & Weeks -2 and -1 (BL) & 143 & 138 & 139 \\
\hline mean (SD) & & $2.222(0.805)$ & $2.304(0.718)$ & $2.248(0.662)$ \\
\hline$n$ & Weeks 1-4 & 141 & 135 & 138 \\
\hline LS mean change (SE) & & $-0.034(0.023)$ & $0.029(0.023)$ & $0.046(0.023)$ \\
\hline Difference vs placebo $(95 \% \mathrm{Cl})$ & & & $0.064(0.000,0.127)$ & $0.080(0.017,0.144)$ \\
\hline$n$ & Weeks 5-8 & 139 & 128 & 135 \\
\hline LS mean change (SE) & & $-0.046(0.027)$ & $0.018(0.027)$ & $0.063(0.027)$ \\
\hline Difference vs placebo $(95 \% \mathrm{Cl})$ & & & $0.064(-0.011,0.139)$ & $0.109(0.034,0.184)$ \\
\hline$n$ & Weeks 9-12 & 135 & 130 & 132 \\
\hline LS mean change (SE) & & $-0.058(0.027)$ & $0.045(0.027)$ & $0.054(0.027)$ \\
\hline Difference vs placebo (95\% Cl) & & & $0.103(0.028,0.178)$ & $0.112(0.037,0.186)$ \\
\hline$n$ & Weeks 13-16 & 128 & 124 & 125 \\
\hline LS mean change (SE) & & $-0.026(0.028)$ & $0.052(0.028)$ & $0.058(0.028)$ \\
\hline Difference vs placebo $(95 \% \mathrm{Cl})$ & & & $0.079(0.000,0.157)$ & $0.084(0.006,0.162)$ \\
\hline$n$ & Weeks 17-20 & 126 & 123 & 124 \\
\hline LS mean change (SE) & & $-0.023(0.029)$ & $0.039(0.029)$ & $0.065(0.029)$ \\
\hline Difference vs placebo $(95 \% \mathrm{CI})$ & & & $0.061(-0.019,0.142)$ & $0.087(0.007,0.167)$ \\
\hline$n$ & Weeks 21-24 & 128 & 123 & 125 \\
\hline LS mean change (SE) & & $-0.038(0.029)$ & $0.033(0.030)$ & $0.081(0.029)$ \\
\hline Difference vs placebo (95\% Cl) & & & $0.071(-0.011,0.152)$ & $0.118(0.037,0.199)$ \\
\hline$n$ & Weeks 1-24* & 142 & 137 & 138 \\
\hline LS mean change (SE) & & $-0.038(0.024)$ & $0.036(0.025)$ & $0.061(0.024)$ \\
\hline Difference vs placebo (95\% Cl) & & & $0.074(0.006,0.141)$ & $0.098(0.031,0.166)$ \\
\hline
\end{tabular}

*Treatment effect averaged over all time points. These analyses were performed using an MMRM model with covariates of treatment, age, sex, region, baseline value and 4-weekly period, and with interaction terms for baseline by period and treatment by period.

$B L$ baseline, $C l$ confidence interval, $F E V$ forced expiratory volume in $1 \mathrm{~s}, L S$ least squares, $M M R M$ mixed model repeated measures, $S D$ standard deviation, $S E$ standard error, UMEC umeclidinium 
A.

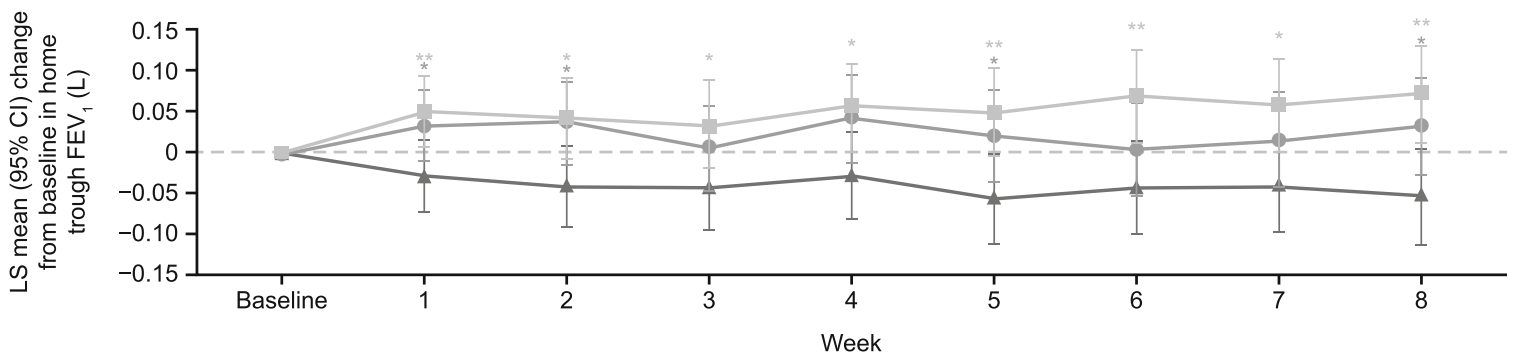

B.

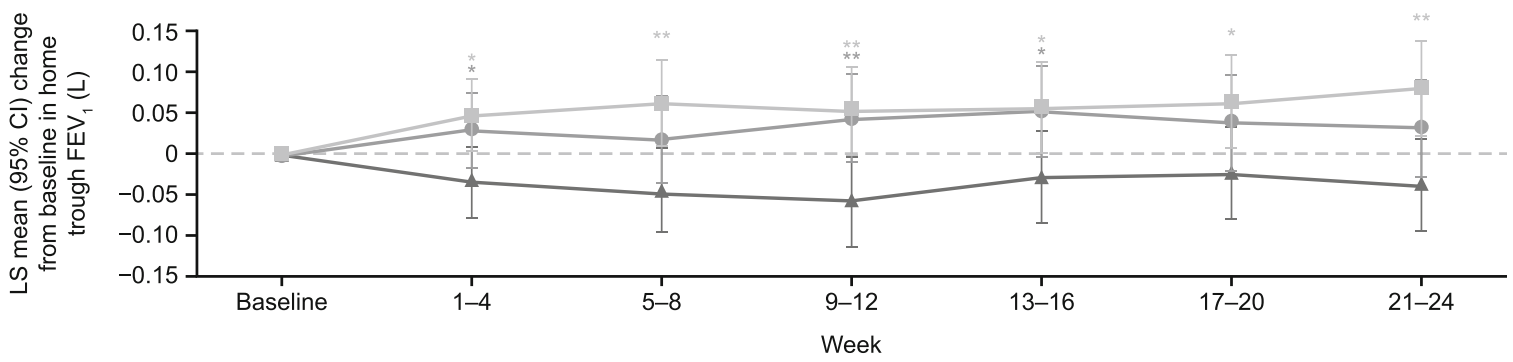

c.

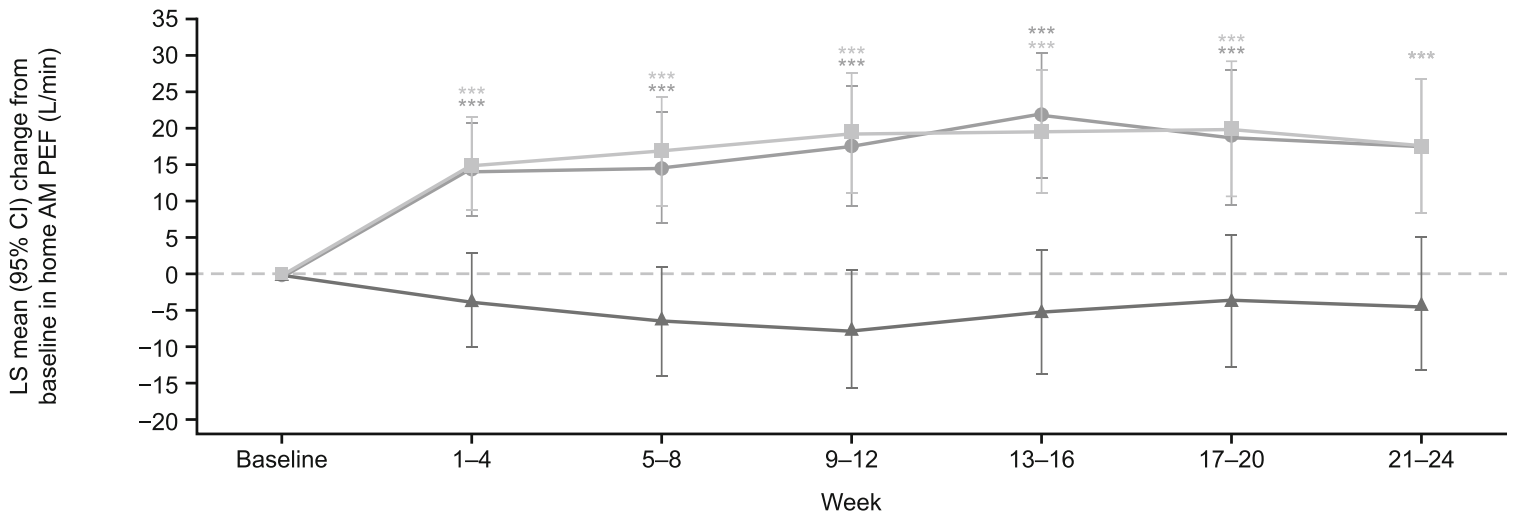

D.

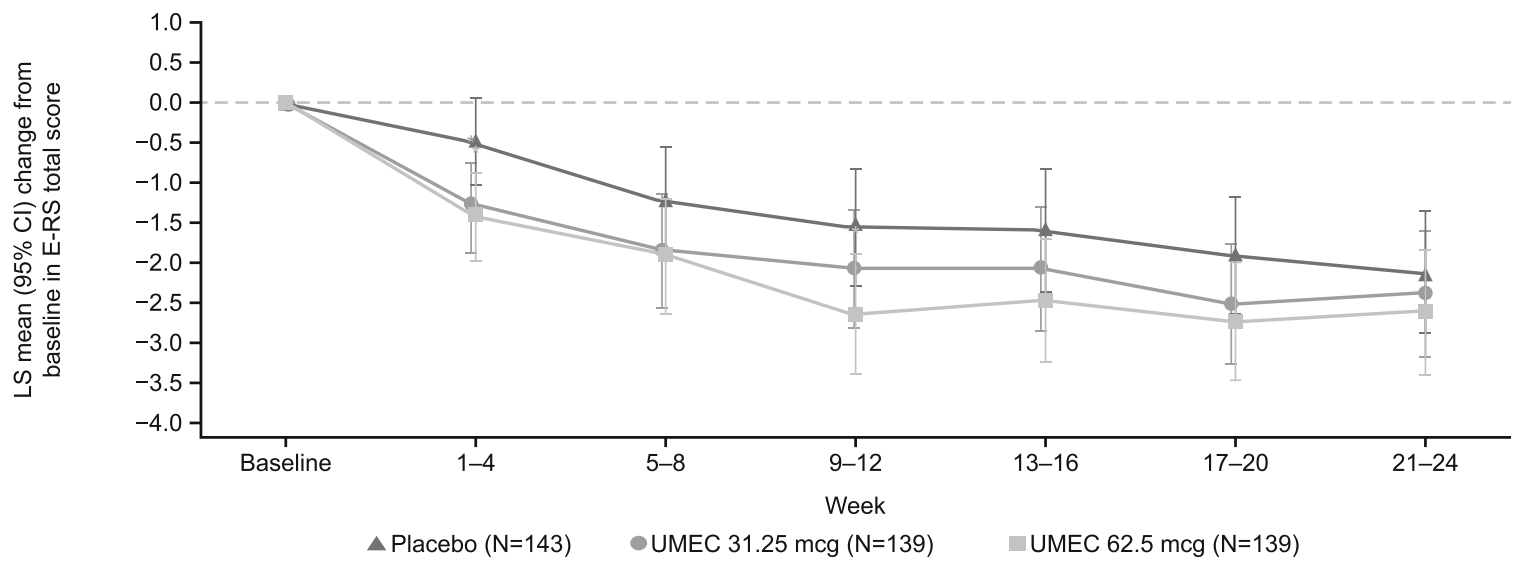

Fig. 3 (See legend on next page.) 
(See figure on previous page.)

Fig. 3 LS mean change from baseline in home spirometry measures and E-RS total scores. LS mean (95\% Cl) change from baseline in (a) home trough $\mathrm{FEV}_{1}$ up to Week 8 by 1-weekly intervals, (b) home trough $\mathrm{FEV}_{1}$ over the 24-week treatment period by 4-weekly intervals, (c) AM PEF over the 24-week treatment period by 4-weekly intervals and (d) E-RS total scores over the 24-week treatment period by 4-weekly intervals (ITT population). Error bars represent $95 \% \mathrm{Cl}$. ${ }^{*} p \leq 0.05 ;{ }^{* *} p \leq 0.01 ;{ }^{* *} p \leq 0.001$, treatment difference from placebo. AM, morning; $\mathrm{Cl}$, confidence interval; E-RS, Evaluating Respiratory Symptoms; FEV 1 , forced expiratory volume in $1 \mathrm{~s}$; ITT, intent-to-treat; LS, least squares, PEF, peak expiratory flow;

UMEC, umeclidinium

UMEC 62.5 mcg versus placebo were seen at Weeks 1-4; however, while numerical differences were observed between the UMEC groups and placebo during the rest of the treatment period, these differences were not statistically significant (Fig. 3d).

Overall, over half of patients met the responder thresholds for SGRQ, AQLQ and ACQ-5 total scores across the treatment groups (Supplementary Table 5). For SGRQ, AQLQ and ACQ-5 total scores, there were no statistically significant differences between the odds of being a responder for UMEC $31.25 \mathrm{mcg}$ or $62.5 \mathrm{mcg}$ versus placebo.

\section{Exacerbations}

Few patients experienced a moderate/severe exacerbation during the study across treatment groups (placebo: 15\%; UMEC 31.25 mcg: 11\%; UMEC 62.5 mcg: 12\%). An equal number of patients experienced a moderate exacerbation (7\%) in each treatment group; however, more patients experienced a severe exacerbation in the placebo group (8\%) than either UMEC group (4\%). A higher number of severe exacerbations were reported in the placebo group (16 events) compared with the UMEC $31.25 \mathrm{mcg}$ (6 events) and $62.5 \mathrm{mcg}$ (7 events) groups. The annualised rates of moderate/severe and severe exacerbations were numerically lower with either dose of UMEC compared with placebo; however, this was only statistically significant for severe exacerbations with UMEC $31.25 \mathrm{mcg}$ versus placebo (rate ratio [95\% CI]: 0.33 [0.12, 0.90]; $p=0.030$; Supplementary Table 6).

\section{Safety}

The incidence of on-treatment AEs was higher in the UMEC 31.25 mcg group (53\%) compared with the placebo (45\%) and UMEC $62.5 \mathrm{mcg}$ (41\%) groups (Table 3 ). This difference did not appear to be driven by any single system organ class or preferred term. Common ontreatment AEs included nasopharyngitis, headache and

Table 3 On-treatment AEs occurring in $\geq 3 \%$ of patients in any treatment group (ITT population)

\begin{tabular}{llll} 
& Placebo $(N=143)$ & UMEC 31.25 mcg (N=139) & UMEC 62.5 mcg (N=139) \\
& $n(\%)$ & $7(\%)$ & $57(41)$ \\
\hline Any AE & $65(45)$ & $73(53)$ & $13(9)$ \\
Nasopharyngitis & $17(12)$ & $14(10)$ & $6(4)$ \\
Upper respiratory tract infection & $3(2)$ & $8(6)$ & $4(3)$ \\
Respiratory tract infection viral & $5(3)$ & $7(5)$ & $4(3)$ \\
Oropharyngeal pain & $2(1)$ & $6(4)$ & 0 \\
Dysphonia & $2(1)$ & $6(4)$ & $12(9)$ \\
Headache & $11(8)$ & $9(6)$ & $5(4)$ \\
Toothache & $4(3)$ & $1(<1)$ & $1(<1)$ \\
Back pain & $5(3)$ & $3(2)$ & $2(1)$ \\
Arthralgia & $1(<1)$ & $5(4)$ & $1(<1)$ \\
Hypertension & $5(3)$ & $4(3)$ & $3(2)$ \\
Drug-related AEs & $4(3)$ & $6(4)$ & $1(<1)$ \\
AEs leading to permanent discontinuation of study treatment & $1(<1)$ & $1(<1)$ & 0 \\
AEs leading to withdrawal from the study & $1(<1)$ & 0 & $3(2)$ \\
Any SAE & $5(3)$ & $4(3)$ & 0 \\
Drug-related SAEs & 0 & 0 & 0 \\
Fatal SAEs & 0 & 0 & 0 \\
Fatal drug-related SAEs & & 0
\end{tabular}


upper respiratory tract infection (Table 3). The incidences of drug-related AEs and SAEs were low and similar across the treatment groups (Table 3). There were no fatalities. The most common AESIs included dry mouth/ drying of the airway secretions, local steroid effects and cardiovascular effects (particularly hypertension), and their occurrences were similar between treatment groups (Table 4). There was a statistically significant LS mean increase from baseline in pulse rate for UMEC $62.5 \mathrm{mcg}$ compared with placebo at Weeks 12 and 24 (Week 12: 1.7 beats $/ \mathrm{min}$ [95\% CI: $0.00,3.30], p=0.045$; Week 24: 3.4 beats $/ \min [95 \%$ CI: $1.30,5.50], p=0.002)$. This observation was at least partially driven by a reduction in the placebo group of 0.6 and 1.6 beats/min respectively for Weeks 12 and 24, and not observed on electrocardiogram. No clinically relevant findings were observed for electrocardiogram or vital signs.

\section{Discussion}

This is the first study to examine the effect of UMEC in patients with asthma and fully reversible airflow obstruction over a 24-week period. Results show that UMEC is an effective bronchodilator in this particular asthma population receiving FF as background therapy. Specifically, UMEC 31.25 and $62.5 \mathrm{mcg}$ demonstrated statistically significant and clinically meaningful improvements in the primary endpoint of clinic trough $\mathrm{FEV}_{1}$ at Week 24 compared with placebo. While an MCID in $\mathrm{FEV}_{1}$ has not been formally defined in asthma, a previous Phase III study of patients with persistent asthma showed that FF $100 \mathrm{mcg}$ and FF/VI 100/25 mcg improved trough $\mathrm{FEV}_{1}$ by $136 \mathrm{~mL}$ and $172 \mathrm{~mL}$, respectively, compared with placebo [25]. We report changes from baseline versus placebo in clinic trough $\mathrm{FEV}_{1}$ of $176 \mathrm{~mL}$ for UMEC $31.25 \mathrm{mcg}$ and $184 \mathrm{~mL}$ for UMEC $62.5 \mathrm{mcg}$ at Week 24; these changes are greater than the change reported with $\mathrm{FF}$ alone and equal to that achieved with FF/VI combined. In addition, in COPD it has been widely reported that a change in $\mathrm{FEV}_{1}$ of $100 \mathrm{~mL}$ is perceptible by patients and correlates with fewer relapses [26].

These results were supported by significantly greater CFB with both UMEC doses versus placebo in the secondary endpoint of clinic $\mathrm{FEV}_{1} 3 \mathrm{~h}$ post dose at Week 24, as well as in other endpoints of daily home trough

Table 4 Summary of on-treatment AESIs (ITT population)

\begin{tabular}{|c|c|c|c|}
\hline & $\begin{array}{l}\text { Placebo } \\
(N=143) \\
n(\%)\end{array}$ & $\begin{array}{l}\text { UMEC } 31.25 \mathrm{mcg} \\
(N=139) \\
n(\%)\end{array}$ & $\begin{array}{l}\text { UMEC } 62.5 \mathrm{mcg} \\
(N=139) \\
n(\%)\end{array}$ \\
\hline Adrenal suppression & 0 & 0 & 0 \\
\hline Anticholinergic syndrome $(S M Q)^{*}$ & $1(<1)$ & $1(<1)$ & $3(2)$ \\
\hline CV effects* & $10(7)$ & $7(5)$ & $6(4)$ \\
\hline Hypertension (SMQ) & $7(5)$ & $5(4)$ & $4(3)$ \\
\hline Cardiac arrhythmia & $1(<1)$ & $1(<1)$ & $1(<1)$ \\
\hline Ischaemic heart disease (SMQ) & $1(<1)$ & 0 & $1(<1)$ \\
\hline Cardiac failure (SMQ) & $1(<1)$ & $1(<1)$ & 0 \\
\hline CNS haemorrhages and cerebrovascular conditions (SMQ) & $1(<1)$ & 0 & 0 \\
\hline Decreased BMD and associated fractures & 0 & 0 & 0 \\
\hline Dry mouth/drying of the airway secretions (broad focus)* & $28(20)$ & $29(21)$ & $27(19)$ \\
\hline Dry mouth/drying of the airway secretions (narrow focus)* & 0 & 0 & $1(<1)$ \\
\hline Gastrointestinal obstruction (SMQ)* $^{*}$ & 0 & 0 & 0 \\
\hline Hyperglycaemia/ new onset diabetes mellitus (SMQ) & $1(<1)$ & 0 & 0 \\
\hline Hypersensitivity* & $3(2)$ & $3(2)$ & $1(<1)$ \\
\hline Infective pneumonia (SMQ)* & $1(<1)$ & $1(<1)$ & 0 \\
\hline LRTI (excluding infective pneumonia SMQ)* & $3(2)$ & $2(1)$ & $6(4)$ \\
\hline Local steroid effects & $5(3)$ & $12(9)$ & $6(4)$ \\
\hline Ocular effects* & 0 & $1(<1)$ & 0 \\
\hline Glaucoma (SMQ) & 0 & $1(<1)$ & 0 \\
\hline Lens disorders (SMQ) & 0 & 0 & 0 \\
\hline Urinary retention* & $1(<1)$ & 0 & 0 \\
\hline
\end{tabular}

*Special interest groups related to UMEC and LAMAs

$A E S I$ adverse event of special interest, BMD bone mineral density, CNS central nervous system, CV cardiovascular, ITT intent-to-treat, LAMA long-acting muscarinic antagonist, LRTI lower respiratory tract infections, MedDRA Medical Dictionary for Regulatory Activities, SMQ standardised MedDRA queries, UMEC umeclidinium 
$\mathrm{FEV}_{1}$ and PEF over Weeks 1-24. The improvements with UMEC in clinic trough and $3 \mathrm{~h}$ post dose $\mathrm{FEV}_{1}$ are of similar magnitude to that of tiotropium in patients with asthma uncontrolled on ICS [8]. Additionally, improvements in $\mathrm{FEV}_{1}$ and PEF in the current study are in line with those seen in patients with asthma treated with vilanterol in addition to FF [12].

Home spirometry has been used in other clinical studies of respiratory conditions including post lung transplantation, idiopathic pulmonary fibrosis, COPD and asthma [27-30]. In the current study, the daily monitoring of lung function endpoints using home spirometry allowed accurate determination of the time course of improvements with UMEC. Both doses of UMEC demonstrated early benefits on home trough $\mathrm{FEV}_{1}$ by Week 1 that were sustained over the 24-week treatment period. This finding was supported by similar early benefits of UMEC on home PEF.

The magnitude of effect for clinic spirometry measurements obtained in this study were generally higher than home spirometry measurements. We speculate this difference may be due to conduct under supervision in a clinic setting. This difference may also be influenced by the time of day at which the measurements were performed, which was later for clinic than home measurements. However, as a treatment effect was observed for both doses of UMEC using both techniques, we conclude that while the use of home spirometry in individual patients may lack sensitivity, the increased frequency of home measurements and lack of systematic bias lends support to the accurate measurement of treatment effects when used in conjunction with more sensitive clinical measurements.

As with standard dose finding studies this study was not powered to directly compare the efficacy and safety of the two UMEC doses, but it can be used to inform appropriate doses for assessment in larger studies in the target population. It is notable that the magnitude of effect with UMEC $62.5 \mathrm{mcg}$ versus placebo was generally numerically greater than UMEC $31.25 \mathrm{mcg}$ versus placebo for all lung function endpoints. This was observed in the first 8 weeks of treatment with home trough $\mathrm{FEV}_{1}$ and at all time points up to and including Week 24, with UMEC $62.5 \mathrm{mcg}$ also showing greater consistency of effect than UMEC $31.25 \mathrm{mcg}$ when compared with placebo.

Numerical improvements in all PRO endpoints from baseline were observed in all treatment groups, including placebo, at Week 24. Although an MCID for E-RS total score has not been defined in asthma, both UMEC $31.25 \mathrm{mcg}$ and $62.5 \mathrm{mcg}$ showed a decrease of $\geq 2$ points, while the placebo group did not. Notably, improvements in E-RS total scores were numerically greater with UMEC $62.5 \mathrm{mcg}$ versus placebo than with UMEC $31.25 \mathrm{mcg}$ versus placebo at all 4-weekly intervals, correlating with the observation that UMEC $62.5 \mathrm{mcg}$ had consistent improvements for home trough $\mathrm{FEV}_{1}$ throughout the 24-week period, particularly over the latter half of the study. However, as this study was not adequately powered for statistical comparison of effects on PROs, a larger study in patients with asthma with a high burden of self-reported symptoms may be needed to more fully evaluate the effects of UMEC in patients with asthma.

Although this was not an exacerbation study, the annual rate and risk of experiencing an exacerbation was numerically lower with FF/UMEC versus FF alone, which supports previous findings showing that LAMAs can improve exacerbation rates and the time to first exacerbation in asthma $[8,10]$. These results are also consistent with and of a similar magnitude to those observed with FF/VI versus FF alone, where the addition of a LABA to ICS reduced the rate of exacerbations [12, 31]. It is of interest that UMEC-treated patients experienced a numerically higher proportion of moderate than severe exacerbations while placebo-treated patients had a slightly higher proportion of severe exacerbations. It could be speculated that UMEC acts by preventing moderate exacerbations from becoming severe; however, the numbers of both moderate and severe events were small. Further studies in larger populations of patients with more severe asthma will be needed to confirm this potential effect of UMEC.

Importantly, the safety profile of UMEC/FF was as expected for this class of medications and no new signals were identified. No UMEC-dose-related increase in AEs was observed, as there was a higher incidence of AEs with UMEC $31.25 \mathrm{mcg}$ compared with UMEC $62.5 \mathrm{mcg}$.

The study had a number of strengths, including the 24-week duration and the robust study design which ensured it was well powered to detect lung function improvements with centrally-measured spirometry. Furthermore, pulmonary function and symptoms were monitored daily, with patients required to record home trough $\mathrm{FEV}_{1}$ and PEF twice daily (AM and PM) and to use an eDiary to record asthma symptoms and rescue medication use. The requirement of daily E-RS total scores allowed for the standardisation of symptom assessment on a daily basis. Additionally, all measures were captured in the home environment when asthma may be at its worst (e.g., in the early AM). There was limited patient withdrawal, and patient follow up continued in patients following treatment cessation prior to 24 weeks. Finally, sensitivity analyses confirmed that the results were robust.

Study limitations included the relatively low burden of asthma symptoms of the included patients at study entry, which, combined with a limited run-in period and an effective background treatment, made differences in 
PRO endpoints between treatment groups difficult to detect in a study of this size, despite improvements in excess of the MCID for all treatment groups. The large placebo responses observed with PRO endpoints may reflect the beneficial effect of adherence to ICS (FF $100 \mathrm{mcg}$ ), which was maintained for 24 weeks. Including a longer run-in period with patients receiving ICS may have provided a more stable baseline and, in conjunction with enrolling patients with poorly controlled asthma (i.e., ACQ >1.5), could have potentially reduced the placebo response. Indeed, data on treatment compliance prior to the study were not collected, therefore, the effect of improved treatment compliance while taking part in the study could not be assessed. While our results provide support for the use of the E-RS in asthma, the E-RS was developed for use in patients with COPD and its modification for use in an asthma population needs to be validated before its routine use is appropriate. Finally, these results are restricted to a population with moderate asthma, limiting their relevance to other populations. However, the effect of UMEC was investigated in a Phase III study including patients with more severe asthma, uncontrolled on ICS/LABA (CAPTAIN, clinicaltrials.gov ID: NCT02924688), which will broaden the understanding of UMEC treatment in the treatment of asthma.

\section{Conclusions}

UMEC is a highly effective once-daily bronchodilator that leads to improved lung function and is well tolerated in patients with fully reversible, uncontrolled/partially-controlled moderate asthma who are receiving ICS. Overall, these data support a favourable benefit/risk profile for UMEC (31.25 mcg and $62.5 \mathrm{mcg}$ ) in this asthma population.

\section{Supplementary information}

Supplementary information accompanies this paper at https://doi.org/10. 1186/s12931-020-01400-5.

Additional file 1. Supplementary Materials. Supplementary Tables 1-6.

\section{Abbreviations}

ACQ: Asthma Control Questionnaire; AE: Adverse event; AESI: Adverse event of special interest; AM: Morning; AQLQ: Asthma Quality of Life Questionnaire; BMD: Bone mineral density; BMI: Body mass index; CAPTAIN: Clinical study of Asthma Patients receiving Triple therapy through A single INhaler; CFB: Change from baseline; Cl: Confidence interval; CNS: Central nervous system; COPD: Chronic obstructive pulmonary disease; CV: Cardiovascular; DPI: Dry powder inhaler; eCRF: Electronic Case Report Form;

eDiary: Electronic diary; EXACT: EXAcerbations of Chronic pulmonary disease Tool; E-RS: Evaluating Respiratory Symptoms; FEV ${ }_{1}$ : Forced expiratory volume in $1 \mathrm{~s}$; FF: Fluticasone furoate; FVC: Forced vital capacity; GINA: Global Initiative for Asthma; ICS: Inhaled corticosteroid; ITT: Intent-to-treat; LABA: Long-acting $\beta_{2}$-agonist; LAMA: Long-acting muscarinic antagonist; LRTI: Lower respiratory tract infection; LS: Least squares; LTRA: Leukotriene receptor antagonist: MCID: Minimal clinically important difference; MDI: Metered dose inhaler; MedDRA: Medical Dictionary for Regulatory
Activities; MMRM: Mixed model repeated measures; PEF: Peak expiratory flow; PM: Evening; PRO: Patient-reported outcome; SABA: Short-acting $\beta_{2}$-agonist; SAE: Serious adverse event; SD: Standard deviation; SE: Standard error; SGRQ: St George's Respiratory Questionnaire; SMQ: Standardised MedDRA queries; UMEC: Umeclidinium; US: United States; V: Visit

\section{Acknowledgements}

Editorial support in the form of initial preparation of the outline based on input from all authors, and collation and incorporation of author feedback to develop subsequent drafts, assembling tables and figures, copyediting, and referencing was provided by Chloe Stevenson, MSci, Hayley Mukherjee, PhD, and Rachael Baylie, PhD, of Fishawack Indicia Ltd, UK, and was funded by GlaxoSmithKline (GSK)

\section{Authors' contributions}

SP and LL contributed to the conception and design of the study, EK, RN and $\mathrm{DB}$ contributed to data acquisition, and $\mathrm{ZB}, \mathrm{RD}, \mathrm{RvM}, \mathrm{KR}, \mathrm{AF}$ and $\mathrm{LL}$ contributed to data analysis and all authors contributed to interpretation. All authors were involved in preparation and review of the manuscript and approved the final version to be submitted.

\section{Funding}

The work presented here, including the conduct of the study, data analysis and interpretation, was funded by GSK (GSK study ID: 205832; clinicaltrials.gov ID: NCT03012061). The sponsor was given the opportunity to review the manuscript for medical and scientific accuracy as well as intellectual property considerations.

\section{Availability of data and materials}

The anonymised individual participant data and study documents can be requested for further research from www.clinicalstudydatarequest.com.

\section{Ethics approval and consent to participate}

The study was conducted in accordance with the ethical principles of the Declaration of Helsinki, International Council for Harmonisation Good Clinical Practice and all applicable country-specific requirements and was approved by relevant national, regional, or independent ethics committee or institutional review board. Written informed consent was obtained from each patient prior to the performance of any study procedures.

\section{Consent for publication}

Not applicable.

\section{Competing interests}

The authors met the criteria for authorship as recommended by the International Committee of Medical Journal Editors. ZB, RvM, KR and AF are employees of GSK and own stock in GSK. SP, RD and LL were employees of GSK at the time of study and own stocks in GSK. EK is an employee of Crisor LLC Research and has served on advisory boards, speaker panels or received travel reimbursement from Amphastar, AstraZeneca, Boehringer Ingelheim, Forest, GSK, Mylan, Novartis, Pearl, Sunovion, Teva and Theravance. EK has conducted multicentre clinical research trials for approximately 40 pharmaceutical companies. RN was an employee of Asthma \& Allergy Associates at the time of the study, and receives grant funding or research support from Aimmune, AstraZeneca, Attenua, Biocryst, Chiesi, Dyax, Genentech, GSK, Lupin, Menlo, Novartis, Pearl, Pfizer, Sanofi Aventis, Shire, Spirosure, Teva, $3 \mathrm{M}$ and Watson. RN is also a consultant or scientific advisor for Boehringer Ingelheim, GSK, Optinose, Stallergenes Greer and CSL Behring and receives speaker's fees from Boehringer Ingelheim, CSL Behring, GSK, Stallergenes Greer and Merck. DB is an employee of the University of Cincinnati College of Medicine and Bernstein Clinical Research Center. DB receives grant/research/clinical trial support from GSK, Teva, AstraZeneca, Pearl, Novartis, Genentech, Lupin, Merck, Mylan, Boehringer Ingelheim, Amgen, Aimmune, Menlo, Shire, Biocryst and provides consultancy or contributes towards advisory boards for GSK, ALK America, Gerson-Lehman and Guidepoint Global. No authors were paid for the development of the manuscript. ELLIPTA is owned by or licensed to the GSK group of companies. 


\section{Author details}

${ }^{1}$ Crisor LLC Research, Clinical Research Institute of Southern Oregon, Medford, OR, USA. ${ }^{2}$ GSK, Upper Providence, PA, USA. ${ }^{3}$ GSK, Stockley Park West, Uxbridge, Middlesex, UK. ${ }^{4}$ Asthma \& Allergy Associates, P.C. and Research Center, Colorado Springs, CO, USA. ${ }^{5}$ Division of Immunology, Allergy and Rheumatology, University of Cincinnati College of Medicine, Cincinnati, OH, USA. 'Bernstein Clinical Research Center, Cincinnati, OH, USA. ${ }^{7}$ GSK, 980 Great West Road, Brentford, Middlesex, UK.

Received: 1 November 2019 Accepted: 19 May 2020

Published online: 12 June 2020

\section{References}

1. GBD 2015 Chronic Respiratory Disease Collaborators. Global, regional, and national deaths, prevalence, disability-adjusted life years, and years lived with disability for chronic obstructive pulmonary disease and asthma, 19902015: a systematic analysis for the Global Burden of Disease Study 2015. Lancet Respir. 2017;5:691-706.

2. Global Initiative for Asthma. Global Strategy for Asthma Management and Prevention 2019. Available from: www.ginasthma.org. Accessed 6 Jan 2020

3. National Institutes of Health (NIH) NH, Lung and Blood Institute. Expert Panel Report 3: Guidelines for the Diagnosis and Management of Asthma 2007. Available from: http:/www.nhlbi.nih.gov/health-pro/guidelines/ current/asthma-guidelines. Accessed 8 Feb 2019.

4. Woodruff PG, Boushey HA, Dolganov GM, Barker CS, Yang YH, Donnelly S, et al. Genome-wide profiling identifies epithelial cell genes associated with asthma and with treatment response to corticosteroids. Proc Natl Acad Sci U S A. 2007;104(40):15858-63.

5. Demoly P, Annunziata K, Gubba E, Adamek L. Repeated cross-sectional survey of patient-reported asthma control in Europe in the past 5 years. Eur Respir Rev. 2012;21(123):66-74.

6. Food and Drug Administration. Highlights of prescribing information for SPIRIVA RESPIMAT. Available from: https://docs.boehringer-ingelheim.com/ Prescribing\%20Information/PIs/Spiriva\%20Respimat/spirivarespimat.pdf. Accessed 26 Feb 2019.

7. Boehringer Ingelheim Limited. Spiriva Respimat 2.5 microgram, inhalation solution. Summary of Product Characteristics. Available from https://www. spiriva.com/global/sites/default/files/spiriva_respimat_spc_march2018.pdf. Accessed 2 June 2020

8. Kerstjens HA, Casale TB, Bleecker ER, Meltzer EO, Pizzichini E, Schmidt O, et al. Tiotropium or salmeterol as add-on therapy to inhaled corticosteroids for patients with moderate symptomatic asthma: two replicate, doubleblind, placebo-controlled, parallel-group, active-comparator, randomised trials. Lancet Respir Med. 2015;3(5):367-76.

9. Kerstjens HA, Disse B, Schroder-Babo W, Bantje TA, Gahlemann M, Sigmund $R$, et al. Tiotropium improves lung function in patients with severe uncontrolled asthma: a randomized controlled trial. J Allergy Clin Immunol. 2011;128(2):308-14.

10. Kerstjens HAM, Engel M, Dahl R, Paggiaro P, Beck E, Vandewalker M, et al. Tiotropium in asthma poorly controlled with standard combination therapy. N Engl J Med. 2012;367(13):1198-207.

11. Peters SP, Kunselman SJ, Icitovic N, Moore WC, Pascual R, Ameredes BT, et al. Tiotropium bromide step-up therapy for adults with uncontrolled asthma. N Engl J Med. 2010;363(18):1715-26.

12. Rodrigo GJ, Plaza V. Once-daily fluticasone furoate and vilanterol for adolescents and adults with symptomatic asthma: a systematic review with meta-analysis. Ann Allergy Asthma Immunol. 2016;1 16(6):565-70.

13. Decramer M, Maltais F, Feldman G, Brooks J, Harris S, Mehta R, et al. Bronchodilation of umeclidinium, a new long-acting muscarinic antagonist, in COPD patients. Respir Physiol Neurobiol. 2013;185(2):393-9.

14. Lee LA, Yang S, Kerwin E, Trivedi R, Edwards LD, Pascoe S. The effect of fluticasone furoate/umeclidinium in adult patients with asthma: a randomized, dose-ranging study. Respir Med. 2015;109(1):54-62.

15. Lee L, Kerwin E, Collison K, Nelsen L, Wu W, Yang S, et al. The effect of umeclidinium on lung function and symptoms in patients with fixed airflow obstruction and reversibility to salbutamol: a randomised, 3-phase study. Respir Med. 2017;131:148-57.

16. Leidy NK, Murray LT, Monz BU, Nelsen L, Goldman M, Jones PW, et al. Measuring respiratory symptoms of COPD: performance of the EXACTrespiratory symptoms tool (E-RS) in three clinical trials. Respir Res. 2014;15:124.
17. Leidy NK, Sexton CC, Jones PW, Notte SM, Monz BU, Nelsen L, et al. Measuring respiratory symptoms in clinical trials of COPD: reliability and validity of a daily diary. Thorax. 2014;69(5):443-9.

18. Nelsen LM, Lee LA, Wu W, Lin X, Murray L, Pascoe SJ, Leidy NK. Reliability, validity and responsiveness of E-RS:COPD in patients with spirometric asthma-COPD overlap. Respir Res. 2019;20(1):107.

19. Jones PW. St. George's respiratory questionnaire: MCID. COPD. 2005;2(1):75-9.

20. Juniper EF, Guyatt GH, Willan A, Griffith LE. Determining a minimal important change in a disease-specific quality of life questionnaire. J Clin Epidemiol. 1994;47(1):81-7.

21. Juniper EF, Svensson K, Mork AC, Stahl E. Measurement properties and interpretation of three shortened versions of the asthma control questionnaire. Respir Med. 2005;99(5):553-8.

22. Reddel HK, Taylor DR, Bateman ED, Boulet LP, Boushey HA, Busse WW, et al. An official American Thoracic Society/European Respiratory Society statement: asthma control and exacerbations: standardizing endpoints for clinical asthma trials and clinical practice. Am J Respir Crit Care Med. 2009; 180(1):59-99.

23. Virchow JC, Backer V, de Blay F, Kuna P, Ljorring C, Prieto JL, et al. Defining moderate asthma exacerbations in clinical trials based on ATS/ERS joint statement. Respir Med. 2015;109(5):547-56.

24. Jones PW. Interpreting thresholds for a clinically significant change in health status in asthma and COPD. Eur Respir J. 2002;19(3):398-404.

25. Bleecker ER, Lotvall J, O'Byrne PM, Woodcock A, Busse WW, Kerwin EM, et al. Fluticasone furoate-vilanterol $100-25 \mathrm{mcg}$ compared with fluticasone furoate $100 \mathrm{mcg}$ in asthma: a randomized trial. J Allergy Clin Immunol Pract. 2014;2(5):553-61.

26. Donohue JF. Minimal clinically important differences in COPD lung function. COPD. 2005;2(1):111-24.

27. Belloli EA, Wang X, Murray S, Forrester G, Weyhing A, Lin J, et al. Longitudinal forced vital capacity monitoring as a prognostic adjunct after lung transplantation. Am J Respir Crit Care Med. 2015;192(2):209-18.

28. Finkelstein SM, Lindgren BR, Robiner W, Lindquist R, Hertz M, Carlin BP, et al. A randomized controlled trial comparing health and quality of life of lung transplant recipients following nurse and computer-based triage utilizing home spirometry monitoring. Telemedicine J e-Health. 2013;19(12):897-903.

29. Menezes MB, Teixeira AL, Terra Filho J, Vianna EO. Inflammatory and functional effects of increasing asthma treatment with formoterol or double dose budesonide. Respir Med. 2008;102(10):1385-91.

30. Russell AM, Adamali H, Molyneaux PL, Lukey PT, Marshall RP, Renzoni EA, et al. Daily home spirometry: an effective tool for detecting progression in idiopathic pulmonary fibrosis. Am J Respir Crit Care Med. 2016;194(8):989-97.

31. Bateman ED, O'Byrne PM, Busse WW, Lotvall J, Bleecker ER, Andersen L, et al. Once-daily fluticasone furoate (FF)/vilanterol reduces risk of severe exacerbations in asthma versus FF alone. Thorax. 2014;69(4):312-9.

\section{Publisher's Note}

Springer Nature remains neutral with regard to jurisdictional claims in published maps and institutional affiliations.

Ready to submit your research? Choose BMC and benefit from:

- fast, convenient online submission

- thorough peer review by experienced researchers in your field

- rapid publication on acceptance

- support for research data, including large and complex data types

- gold Open Access which fosters wider collaboration and increased citations

- maximum visibility for your research: over $100 \mathrm{M}$ website views per year

At BMC, research is always in progress.

Learn more biomedcentral.com/submissions 